\title{
The Well-Being of Adolescents in Northern Canada
}

Peter Burton, Angela Daley and Shelley Phipps

Department of Economics, Dalhousie University

angela.daley@dal.ca

\section{Introduction}

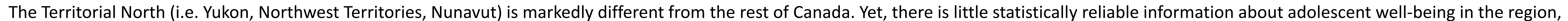

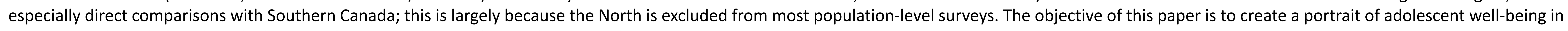
the Territorial North, benchmarked against the same indicators for Southern Canada.

\section{Methodology}

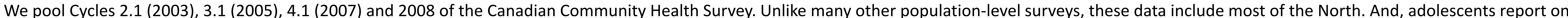

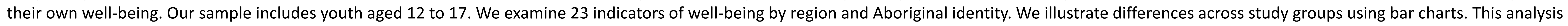
is purely descriptive; we do not infer relationships between indicators or explain differences across study groups.

\section{Findings}
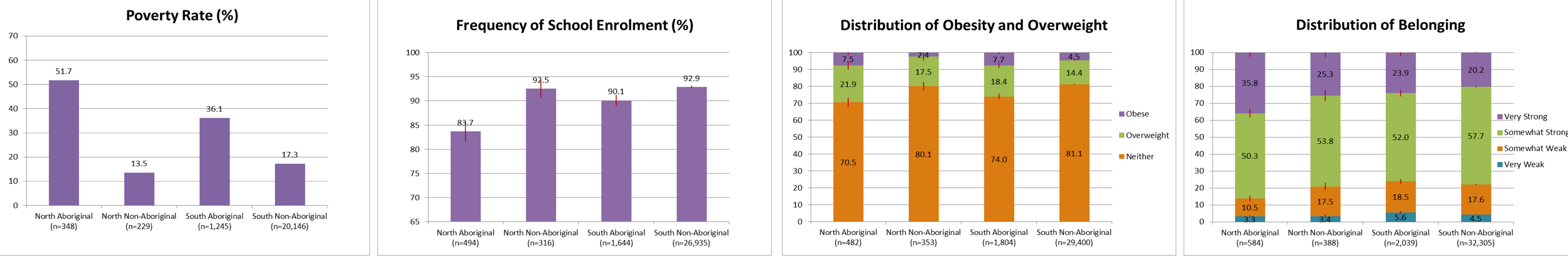

Distribution of Food Insecurity

100
90
80
70
60
50
40
30
20
10
0
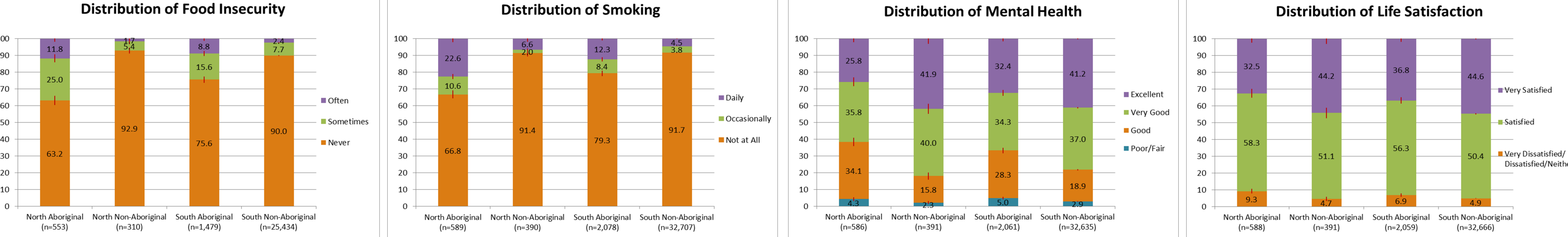

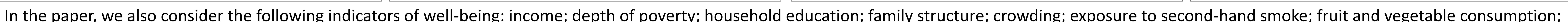
physical activity; drinking; sexual activity; asthma; activity limitations; oral health; overall health; stress; and body image.

\section{Conclusions}

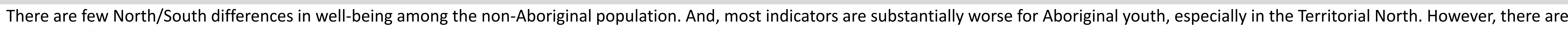

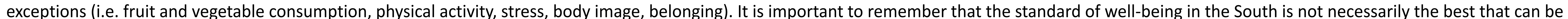

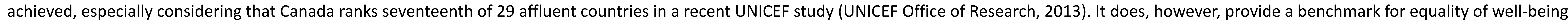
among Canadian adolescents.

\section{Reference}

UNICEF Office of Research (2013). Child well-being in rich countries: A comparative overview. Innocenti Report Card 11. Florence: UNICEF Office of Research.

\section{Acknowledgements}

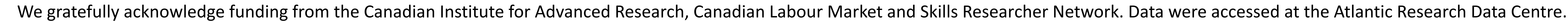

